\title{
Exceptional location of a migrating esophageal foreign body: report of two cases
}

\author{
Abstract \\ Introduction: Esophageal perforations due to foreign bodies are rare but can be life- \\ threatening. They complicate 1 to $4 \%$ of ingestion of foreign objects; organic type of edges \\ and bone. The migration to carotid sheath vascular bundle is a rare situation The prognosis \\ largely depends on the time of diagnosis and the choice of the first line treatment modality. \\ Observations: We report two cases of esophageal perforation due to foreign body, which \\ migrates to the carotid sheath between the carotid artery and internal jugular vein. X- Ray \\ and CT had confirmed the foreign body. Foreign bodies are removed with cervical incision \\ and abscess drained.
}

Conclusion: The surgery associated with antibiotic therapy has allowed a favorable outcome.

Keywords: perforation, cervical incision, foreign body, carotid sheath
Volume 8 Issue 5 - 2017

\author{
Houra Ahmed, Cire Ndiaye, Evelyne S Diom, \\ Modibo Doumbia, Issa C NDiaye \\ Cheikh Anta Diop University, Senegal
}

Correspondence: Houra Ahmed Cheikh Anta Diop University University in Dakar, Senegal, Email houraza@yahoo.fr

Received: June 16, 2017| Published: September 18, 2017

\section{Introduction}

The foreign bodies of the esophagus are observed at any age. They are more common in children. The nature of foreign body depend on eating habits or age of patient. The complications are rare and are related either to the type of these foreign bodies or the mechanism of extraction. The extraluminal migration of foreign body through the oesophagus is known to cause bleeding and perforation These perforations are associated with severe morbidity, which cause disabling sequelae. The diagnosis is based on clinical examination, cervico-thoracic X ray and endoscopy. The surgical exploration allowed the drainage of the abcess and the extraction of foreign body.

\section{Clinical cases}

Case 1: A 40-year-old man, with no previous medical history, consulted for high dysphagia, a fever. The notion of fish bone ingestion, evolving for 5 days was found. Clinical examination revealed an inflammation on the posterior wall of the oropharynx. A cervical x-ray and a CTScan showed the foreign body (Figure 1). Endoscopy did not found the foreign body Surgical exploration (Figure 2) allowed the drainage of the abscess, and extraction of the fish bone. Parenteral antibiotic was administrated. After 45days, patient was reviewed without particularity.

Case 2: A 24-year-old man complaining of torticollis, and dysphagia, evolving for 6 days. The patient reported ingestion of fish bone. The clinical examination founded, hypersialorrhea, a painful cervical node. $\mathrm{X}$ ray showed the foreign body (Figure 3 ). The extraction of the fish bone (Figure 4), the drainage of abscess and the trimming of the oesophageal wound were done by external surgical approach. During the extraction the carotid was notched. One month later, clinical and radiological examination were normal.

\section{Discussion}

Digestive Foreign bodies are commun, and represent $11 \%$ of all ENT emergencies. ${ }^{1}$ By their nature or their location, foreign body can be dangereous. ${ }^{2}$ Foreign bodies can occur at any age, so they are more frequent in children. ${ }^{3}$ The oesophageal foreign body is usually accidental occurring during meals. The luminal and extraluminal migration of an oesophageal foreign body is known.

AG Mohamed and Timbo reported respectively a migration to the right cervical wall, the thorax, and the thyroid gland. ${ }^{4,5}$ However the migration of a foreign body to the vascular sheath remains exceptional.

The emplacement of the foreign body around vascular sheath is possible by transversal migration, step by step. Oesophageal perforations caused by foreign body are related to bone and fish bone. ${ }^{6}$

There are two mechanism for the migration: In direct mechanism the perforation is caused by sharp foreign bodies; in the indirect mechanism the perforation result to the necrosis tissue due by the pressure by the foreign body on the esophageal mucosa beyond 24hours. ${ }^{7}$ In our case, it was difficult to identify the mechanism, because we received both of patients with sharp fish bone and evolving beyond 24 hours.

The patients often report retrosternal pain, dysphagia or vomiting. However a abscess, a cellulitis or a mediastinitis could be observed at the first examination. ${ }^{3}$ Many of these signs are found in our patients. The cervical X Ray allowed the detection of fish bone and the perforation.

Thus in the early cases cliches show the presence of air in the prevertebral area (Minigerode sign). In late cases, an abscess may be suspected on CT scan by an enlarged retropharyngeal space, disappearance of the cervical lordosis or an anterior displacement of the esophagus and the trachea. ${ }^{8}$

CT Scan remains the gold standard for the diagnosis of esophageal perforations, the extension of cellulitis and abscesses in the deep cervical spaces or mediastinum. Endoscopy is an essential step in determining the characteristics of the perforation and the state of the mucosa.

The treatment is medical and surgical and antibiotherapy is systematical in case of migration. ${ }^{7}$ Complicated foreign bodies of the esophagus requiring external oesophagotomy are rather rare, as reported by Lascombes et al., ${ }^{9}$ 


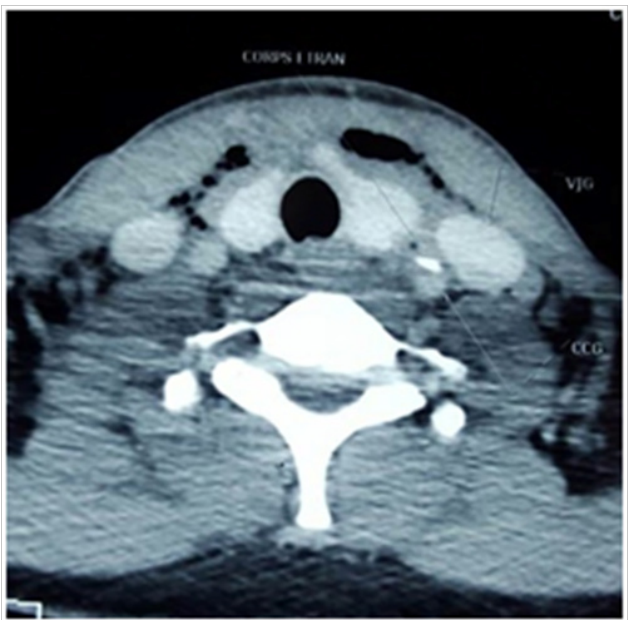

Figure I A cervical x-ray and a CT-Scan showed the foreign body betwen jugular vein and carotid.

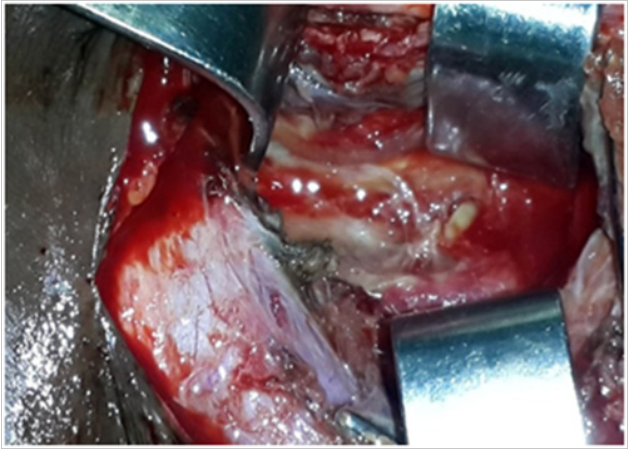

Figure 2 Intraoperative picture of the removal of the foreign body. The drainage of the abscess and extraction of the bone fish.

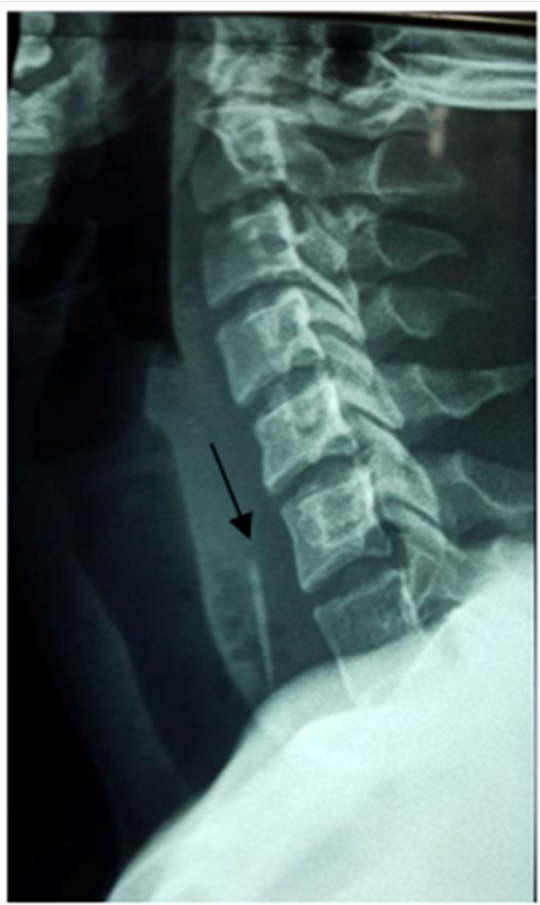

Figure $3 \mathrm{C}$-ray shwed foreign body at c6c7.

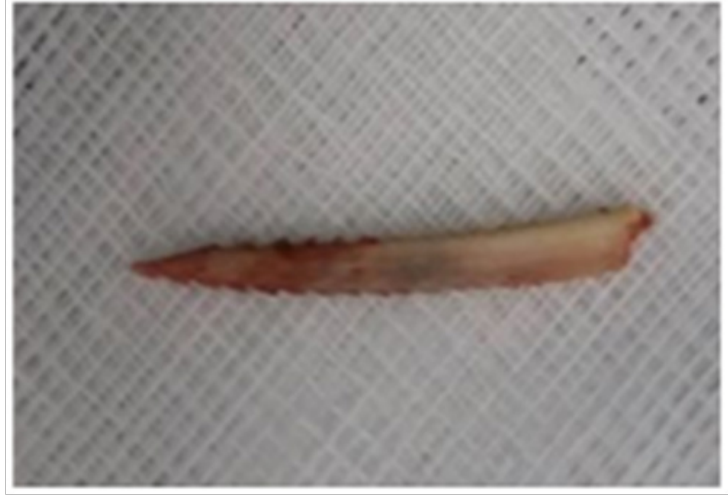

Figure 4 Fish bone.

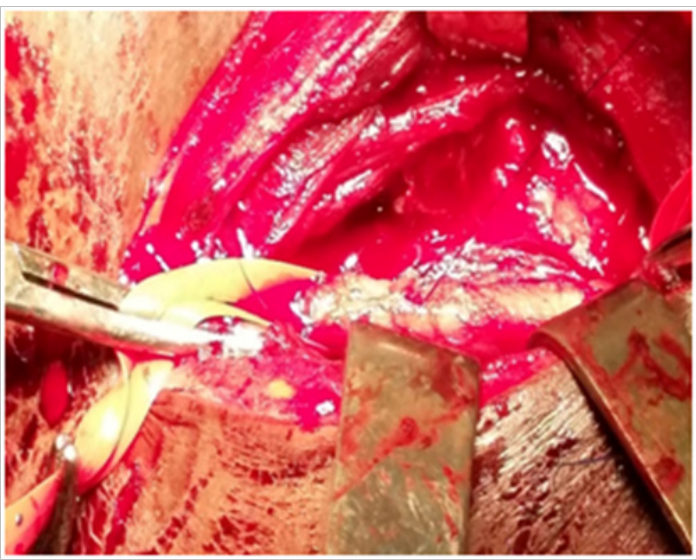

Figure 5 During cervicotomy carotid was notched (flèche).

We are agree with N'gattia et al., ${ }^{10}$ that cervicotomy must be quickly performed in case of perforation with or without neck abscess due to sharp or voluminous bodies. Nevertheless, the extraction must be done carefuly, for avoid vascular lesion, such in our case. We suggest to secure the vascular sheat during the extraction of these sharp fish bone. Despite the gravity of the lesion, postoperative outcome is good. It's explained by the use of broad-spectrum antibiotics nowadays. We would like to insist on the particularity of health conditions in our country. The delay in consultation and the access to CT scan are also limits factors in the management of migrant foreign body.

\section{Conclusion}

In these cases, we want to interest practitioners about the gravity of exceptional migration of fish bone to vascular sheath. The prognosis of these migrant foreign bodies depends essentially on the early diagnosis, treatment and quality of postoperative management. We advise to protect the cervical vascular sheath during any cervicotomy.

\section{Conflicts of interest}

The authors report no conflict of interest.

\section{Acknowledgments}

None.

\section{Funding}

None. 


\section{References}

1. Gyebré MC, Ouattara M, Elola M, et al. UN corps etrnger insolite de l'œsophage. Journal Tunisien d'ORL et de Chirurgie Cervico-Faciale . 2012;28: 80-82.

2. Khaoula H, Btissam B, Youssef R, et al. Les corps étrangers en ORL: expérience de dix. Pan Afr Med J . 2015;21:91.

3. Haennig A, Bournet B, Jean-Pierre . Conduite a tenir devant une ingestion de corps étrangers HEPATO Y GASTRO .Oncologie digestive. 2011;18(3):249-257.

4. Mohamed AG. A Cervicotomie pour extraction d'un corps étranger de l'œsophage. A propos d'un cas. Médecine d'Afrique Noire. 1993;40(4):287.

5. Timbo Sk, keita MA, Yena S, et al. Migration transversale de corps étranger: un cas de hameçon ingéré. Med Afr Noire. 2009;56(2):73-76.

6. Rosiere A, Michel L, Scavée, et al. Traitement des perforations œsophagiennes EMC Techniques chirurgicales - Appareil digestif, Africa. 2004. p. 40-220.

7. Zrig A, Zaara B, Gassab E. les perforations hypopharyngoesophagiennes : Intérêt de l'imagerie. Journal de radiologie. 2009;90(10):1565.

8. MULER H. Les corps étrangers de l'œsophage. EM-consulte, la référence des professionnels de santé. 1971. p. 9-203.

9. Lascombe J, Haeffner G, Ette A. L'œsophagotomie externe: Réflexion à propos de 16 corps étrangers de l'œsophage compliqués. Les cahiers d'ORL. 1993;7:609-612.

10. N'gattia KV, Kacouchia NB, Kouassi YM, et al. Extraction of the oesophageal foreign bodies by cervicotomy: our experience about 9 cases. Rev Laryngol Otol Rhinol. 2011;132(2):123-128. 